\title{
Direitos Fundamentais e Direitos Humanos: o estreitamento das fronteiras conceituais e a necessidade de um diálogo entre a órbita jurídica interna e internacional ${ }^{*}$
}

\author{
Recebido: 4 de fevereiro de 2018 • Aprovado: 12 de dezembro de 2018 \\ https://doi.org/10.22395/ojum.v18n37a8
}

Amélia Sampaio Rossi*

\begin{abstract}
RESUMO
Os Direitos Humanos Fundamentais são, atualmente, o cerne dos sistemas jurídicos democrático-constitucionais e do discurso jurídico, político e social utilizados em resoluções de conflitos domésticos ou internacionais. A pessoa humana é um valor que deve ser protegido pela ordem jurídica interna de Estados nacionais, mas também um valor que merece especial proteção jurídica no âmbito internacional. Assim, neste trabalho, realizado por meio de pesquisa bibliográfica e documental, que utilizou o método histórico-dialético, afirma-se que a diferença das expressões "direitos humanos" e "direitos fundamentais" não subsiste. Elas são inúteis para expressar a delimitação espaço-territorial e injustificáveis no contexto de mundo globalizado e na perspectiva de um constitucionalismo plural.

Palavras-chave: Direitos Humanos e Fundamentais; moral rights; Direito Constitucional Internacional dos Direitos Humanos.
\end{abstract}

Este artigo científico resulta de pesquisa de mestrado realizada no Programa de Pós-graduação em Direitos Humanos e Políticas Públicas da Pontifícia Universidade Católica do Paraná, Curitiba, Brasil.

** Bacharel em Direito pela Universidade Federal do Paraná, Curitiba, Brasil. Mestre em Direito pela Universidade Federal do Paraná, Curitiba, Brasil, e doutora em Direito pela Universidade Federal do Paraná, Curitiba, Brasil. Professora titular de Direito Constitucional da Escola de Direito da Pontifícia Universidade Católica do Paraná, Curitiba, Brasil. Professora no mestrado do Programa de Pós-graduação em Direitos Humanos e Políticas Públicas da Pontifícia Universidade Católica do Paraná, Curitiba, Brasil. Correio eletrônico: amelia.rossi@pucpr.br. Orcid: http//orcid.org/0000-0003-2199-9805 


\section{Derechos Fundamentales y Derechos Humanos: el estrechamiento de las fronteras conceptuales y la necesidad de un diálogo entre la órbita juridica interna e internacional}

\section{RESUMEN}

Actualmente los Derechos Humanos Fundamentales son el núcleo tanto de los sistemas jurídicos y las democracias constitucionales, como del discurso jurídico, político y social utilizado en las resoluciones de conflictos nacionales o internacionales. La persona humana es un valor que debe ser protegido por el ordenamiento jurídico interno de los Estados, además es un valor que merece especial protección jurídica en el ámbito internacional. Así, el artículo es el resultado de una investigación bibliográfica y documental en la que se aplica el método histórico-dialéctico para afirmar que ninguna diferencia subsiste entre las expresiones "derechos humanos" y "derechos fundamentales". Distinguir entre estas dos categorías resulta inútil para expresar la delimitación del espacio territorial e injustificable en el contexto del mundo globalizado y en la perspectiva de un constitucionalismo plural.

Palabras clave: Derechos Humanos y Fundamentales; moral rights; Derecho Constitucional Internacional de los Derechos Humanos.

\section{Fundamental Rights and Human Rights: the Narrowing of the Conceptual Frontiers and the Necessity of a Dialogue Between the Internal and International Legal Orbit.}

\section{ABSTRACT}

Nowadays the Fundamental Human Rights are the core of the legal systems and democratic constitutions, as well as the legal, political and social discourse used in the resolution of national or international conflicts. The human person is a value that must be protected by the internal legal ordering of Stated, furthermore, it is a value the deserves special legal protection on the international scale. Thus, this article is the result of documental and bibliographical research in which the historical-dialectical model is applied for stating that there is no difference between the expressions "human rights and "fundamental rights". Distinguishing these two categories is useless for expressing the circumscription of the territorial space and unjustifiable in the context of a globalized world and the perspective of plural constitutionalism.

Keywords: Human and Fundamental Rights; moral rights; Constitutional International Right of Human Rights. 


\section{INTRODUCÃO}

Como se sabe, a evolução do reconhecimento dos Direitos Humanos e Fundamentais está voltada, principalmente, a estabelecer os traços iniciais do longo caminho percorrido pela luta por reconhecimento, identidade, visibilidade e emancipação das pessoas e grupos que passaram e ainda passam por situações de exclusão de sua própria dignidade. Não é equivocado se afirmar que esses direitos formam, atualmente, o cerne dos sistemas jurídicos democrático-constitucionais e do discurso político e social, especialmente utilizados para resolver conflitos internos ao próprio Estado ou ainda conflitos de cunho internacional. Isso porque a pessoa humana é um valor a ser protegido pela ordem jurídica interna de Estados concretos e determinados, mas, ao mesmo tempo, se coloca como um valor supraestatal, merecedor de especial proteção no âmbito internacional, a tal ponto de ser reconhecido hoje como um processo de constitucionalização do Direito Internacional. Essa empreitada não pode prescindir de uma análise histórica, que aproxime as principais construções teóricas contextualizadas a seu tempo com a própria evolução da ordem estatal e da ordem jurídica que lhe dá consistência.

Para tratar da evolução dos Direitos Humanos e Fundamentais e, por conseguinte, tentar compreender se a diferenciação ainda mantida entre as duas expressões guarda sentido, é necessário, desde o início, perceber a ideia da existência de um fio condutor que perpassa o surgimento histórico de dimensões desses direitos antes mesmo de se delinearem propriamente e com maior clareza como direitos fundamentais positivados, no final do século XVIII, concomitantemente ao desenvolvimento do constitucionalismo moderno liberal. A ideia de moral rights, conforme Pietro Costa (2014) desenvolveu, ajuda a entender o fio condutor que enlaça a compreensão de ambas as expressões.

É preciso também atentar para a mudança nos contornos do Estado e da compreensão de sua própria soberania, nos últimos tempos, introduzidas pela perspectiva da globalização nas suas mais variadas dimensões. É necessário voltar a atenção igualmente às mudanças na órbita jurídica interna dos Estados, em especial à sua órbita constitucional, promovida pelo que se convencionou chamar de "neoconstitucionalismo", "constitucionalismo de direitos" ou "constitucionalismo contemporâneo", que toma como horizonte de sentido da própria Constituição os Direitos Humanos Fundamentais, ao mesmo tempo que se delineia um Direito Constitucional Internacional dos Direitos Humanos, em muito promovido ou facilitado por meio das mudanças introduzidas pela globalização.

Nesse sentido, faz-se necessário que se repensem as relações entre o Direito Interno e o Internacional para além das perspectivas monistas ou dualistas. Essas mudanças anteriormente citadas têm permitido o desenvolvimento e o fortalecimento 
da tomada de consciência de que o indivíduo só poderá estar melhor e mais integralmente protegido em seus direitos quando as órbitas jurídicas internas (dimensão constitucional de proteção aos Direitos Humanos Fundamentais) e internacionais (sistemas internacionais de proteção aos Direitos Humanos) se harmonizarem em um diálogo frutífero que tem por objeto comum elevar a dignidade e o respeito à pessoa humana em níveis universais.

Não se pode esquecer que o objeto do Direito Internacional dos Direitos Humanos e o objeto do constitucionalismo contemporâneo são os mesmos, ou seja, a proteção à pessoa humana em sua integralidade. Assim, ao pensar-se na compreensão de um Direito Constitucional Internacional conforme a ideia de alguns doutrinadores, aponta-se para a perda crescente de sentido na diferenciação entre as expressões.

\section{MORAL RIGHTS COMO UM FIO CONDUTOR PARA COMPREENDER A PROXIMIDADE CONCEITUAL ENTRE DIREITOS HUMANOS E DIREITOS FUNDAMENTAIS}

É de grande auxílio o entendimento de Pietro Costa (2014, p. 31) ao estabelecer como elemento de conexão entre a atual fase em que se encontram os Direitos Humanos e os Direitos Fundamentais, e a visão de ambos como moral rights.

Ao usar a expressão "moral rights", o autor italiano pretende destacar que ela implica um reconhecimento de reivindicações tidas como legítimas e fundadas, presentes no discurso público independentemente do seu reconhecimento ou recepção legal. Essas reivindicações eivadas de legitimidade não se confundem com o direito natural; antes, deve-se considerar que este é uma espécie do gênero moral rights.

Os direitos como moral rights assumem a máxima pretensão de universalidade e são considerados inerentes ao próprio ser humano e, portanto, absolutos em função de não cederem ante outros valores. Nesse sentido, esses direitos ou reivindicações de legitimidade estão intrinsicamente ligados ao indivíduo e são, portanto, componentes indispensáveis da subjetividade.

Para Pietro Costa (2014, p. 33), é possível voltar-se na história até uma figura que representaria, por meio de seu pensamento, a existência dos moral rights. Francisco de Vitória, para o historiador italiano, seria, na Espanha de 1500, um dos precursores da ideia de Direitos Humanos. O teólogo espanhol argumentava no sentido da existência de direitos com caráter universal, mas que não se reconduziam a um sujeito individual. O centro de debates na Espanha da época era a legitimidade das guerras de conquista ou de uma guerra justa (período das grandes navegações e conquista da América, bem como da necessidade de reconhecer o outro, o bárbaro, o índio) e a violação ao jus gentium. Assim, 
[n]on sono i soggetti e i loro diritti il punto di Archimede su cui far leva per rappresentare l'ordine: al contrario, è nella cornice di un ordine gerarchico e differenziato che Vitoria continua a collocare i soggetti. Al contempo però Vitoria è in grado di guardare oltre (o "attraverso") le differenze di potere e di status e affermare che ogni essere umano viene investito dal Creatore di un potere legittimo di disposizione di sé e delle cose esterne, di uno ius-dominium che può essere assunto come il vero e proprio contrassegno del carattere pienamente "umano" di un essere vivente. Il dominium infatti, per una lunga tradizione che trova nella scolastica spagnola illuminanti conferme, prima di essere possesso delle cose esterne, è «dominium super proprios actus et super própria membra», è diritto di esercitare il pieno controllo sulla propria persona, di difendersi, di conservare se stesso. Questo dominium è, sì, un dono di Dio, ma è un dominium naturale, che spetta a ogni uomo e non è cancellato dal peccato o dall'eresia (Costa, 2014, p. 33).'

Conforme já afirmado, os Direitos Naturais também se encaixam, a seu tempo, como uma espécie do gênero moral rights. Nesse senso, compreende Costa (2014) que, ainda que esses direitos tenham encontrado em Francisco de Vitória o seu precursor inicial, será por meio do jusnaturalismo que se estabelecerá, como matriz teórica do moderno discurso de Direitos Humanos (e também dos direitos fundamentais), o nexo intransponível entre esses direitos e o sujeito humano, os direitos do homem, partícipe da natureza humana.

O discurso jusnaturalista dos idos de 1700 encontra nos contratualistas a sua base de difusão; o contratualismo que, por sua vez, inaugura o relato político moderno encontra no indivíduo o ponto de partida de sua construção. Já com Hobbes, considerado o primeiro contratualista, será possível perceber essa trajetória. Para ele, o homem primitivo, em sua condição natural e hipotética, será marcado pelo egoísmo e pela violência, o que justifica a saída dessa condição pré-social e a passagem, por meio do contrato hipotético entre os homens, para a vida na sociedade civil, onde o homem poderá alcançar a paz e a segurança. É claro que Hobbes está, com sua visão contratualista, buscando o caminho de uma reconstrução puramente racional da origem e do fundamento do Estado, e encontra, na base da sociedade e do poder, o indivíduo. Costa (2014) compreende a origem da concepção de Direitos Humanos presente no relato contratualista, que, por sua vez, encontra base nas perspectivas jusnaturalistas de compreensão da origem da sociedade e dos direitos. É necessário

\footnotetext{
"Não são os sujeitos e os seus direitos o ponto de Arquimedes, no qual confiar para representar a ordem: ao contrário, é no quadro de uma ordem hierárquica e diferenciada que Vitória continua a colocar os sujeitos. Ao mesmo tempo, no entanto, Vitória é capaz de olhar para além (ou "através") das diferenças de poder e status e afirmar que todo ser humano é investido pelo Criador de um poder disposição legítima de si mesmo e das coisas externas, de um ius-dominium que pode ser assumido como a verdadeira marca do caráter plenamente "Humano" de um ser vivo. De fato o dominium, por uma longa tradição que se encontra na Escolástica Espanhola confirmada pelo iluminismo, antes de ser posse das coisas externas, é «dominium super proprios actus et super própria membra», é o direito de exercer o controle pleno sobre sua própria pessoa, defender, preservar-se. Este dominium é, sim, um dom de Deus, mas Dominium natural, que respeita a cada homem e não é cancelado pelo pecado ou heresia." (tradução nossa).
} 
demarcar aqui que esta é também a base filosófica de compreensão do nascimento e reconhecimento dos Direitos Fundamentais Positivados e da própria ideia de constituição compreendida como instrumento de retomada de um antigo e hipotético pacto social. Não se pode olvidar que, para alguns doutrinadores, inclusive, Hobbes e sua teoria contratualista teriam lançado as sementes da perspectiva positivista do Direito.

Em outras visões contratualistas, que fazem parte do relato político moderno, encontra-se, vez por outra, na caracterização do estado de natureza, o homem primitivo como portador de direitos, entre estes, principalmente, o direito à propriedade privada, a ideia do trabalho assalariado e a naturalização do livre acordo de vontades entre desiguais. Os contratualistas caracterizam o consenso na formação do Estado, e a segurança, na sua função, em especial, de manter o respeito aos contratos. A ordem instaurada deve ser pensada como uma ordem artificial para que, então, possa ser disponível e manipulável. Nas palavras de Capella (2002),

Na mitologia política da modernidade o estado de natureza serve para apresentar como naturais, portanto, a propriedade privada, o trabalho assalariado (com a acumulação privada) e os pactos entre desiguais. Como conseqüência disso também aparecerá como natural o mercado capitalista. Sendo naturais, o artificial poder político não estará legitimado para interferir neles. [...] Assim, a noção de "estado de natureza", que se concebe sempre como uma hipótese teorética ou de razão para reflexionar sobre o poder político, e não como um estado histórico empírico concreto, permite que a razão legitime as instituições básicas da economia capitalista — propriedade, trabalho assalariado, acumulação e contrato abstrato - antes que o poder político ou estatal entre em linha de conta (Capella, 2002, p. 109).

Observe-se que, na perspectiva contratualista, a ordem agora repousa sobre o sujeito e este, em função das correntes jusnaturalistas, é considerado titular de direitos imanentes. Na visão contratualista de Locke, explica Pietro Costa (2014, p. 36), todos os homens, em sua condição natural, são livres e iguais ou, em outras palavras, são todos (universalmente) livres e proprietários. Iguais porque proprietários do próprio corpo e, em consequência, da produção externa gerada pelo trabalho do homem na transformação da matéria. É o trabalho que agrega valor às coisas, é o trabalho que funda e legitima a propriedade. O corpo concentra sua energia de trabalho em um bem e, desse modo, separa-o da sua originária propriedade coletiva e agrega-o à esfera pessoal do sujeito. Assim,

[él il corpo che agisce appropriandosi dei beni esterni, ma il corpo è a sua volta un oggetto in proprietà di un self, il cui elemento caratterizzante è ancora una volta la ragione. L'antica associazione fra soggettività, razionalità, autocontrollo e proprietà è presente in Locke come in Tommaso o in Vitoria. Ora però il nesso fra razionalità e proprietà produce effetti che investono non solo la sfera del soggetto, ma l'intero assetto dell'ordine sociale-naturale (Costa, 2014, p. 37). ${ }^{2}$

2 "É o corpo que atua apropriando-se de bens externos, mas o corpo por sua vez é um objeto na propriedade do homem mesmo, cujo elemento característico mais importante é ainda uma vez mais 
O universalismo, na perspectiva de direitos em Locke, é evidente. Todos os homens são igualmente livres e proprietários. A ideia de universalidade dos direitos e a vinculação destes com os indivíduos ganham o discurso político e jurídico da época; no entanto, a noção de universalidade e o postulado da igualdade não eliminam a possibilidade do reconhecimento de diferenças entre os indivíduos (os que produzem e os que não produzem valor com o seu trabalho - a propriedade vinculada ao mérito do trabalho produtivo). Assim, todos são igualmente titulares de direitos, mas os verdadeiros sujeitos desses direitos são estabelecidos culturalmente, pelas características de cada uma das sociedades. Portanto, o universalismo se coaduna com a possibilidade de reconhecer as diferenças socialmente dominantes. Outra possibilidade de reconhecimento das diferenças no axioma da igualdade é em relação à questão de gênero. Para Costa (2014, p. 44), a expressão "direitos do homem", cunhada pelos jusnaturalistas, não se refere em um sentido genérico a todos, mas precisamente ao homem, gênero masculino, ao homem-proprietário. Raça, gênero, propriedade delimitam a classe ou o círculo dos sujeitos iguais.

Assim, transcorre a trajetória dos Direitos Humanos e, a este ponto, não é despiciendo lembrar que essa trajetória também perpassa e até se confunde com a própria história de evolução da Instituição Estatal. Dessa maneira, é possível afirmase que os Direitos Humanos se tornam singular e positivamente reconhecidos como direitos civis com o advento do Estado liberal de Direito, em fins do século XVIII. Aí repousa, para alguns, o sentido de se falar de Direitos Fundamentais.

A modernidade própria do "século das luzes" propõe a ideia da existência de determinados princípios universais e atemporais (moral rights) que o homem acessa por meio de sua racionalidade. O Direito Natural, de cunho racionalista, pregará a vinculação entre norma e valor, direito e moral. A seu tempo, em função da revolução, os Direitos Naturais se transformarão em Direitos Civis Positivados.

A visão jusnaturalista de um direito racional e sistêmico será transposta e positivada para os códigos e Constituições escritas de tal modo que o fundamento do direito logo deixará de ser buscado na razão e passará a encontrar-se na vontade do legislador. As sementes de um legalismo exacerbado começam a ser plantadas a partir deste desenvolvimento (Rossi e Gomes, 2014, p. 67).

No entanto, ao contrário do que se poderia esperar, desenvolve-se mais a perspectiva positivista do Direito do que a jusnaturalista. A razão calculista e abstrata substitui a fé e o misticismo do medievo, e faz com que o poder ganhe uma legitimação laica. É

a razão. A antiga associação entre a subjetividade, a racionalidade, auto-controle e propriedade está presente em Locke como em Tommaso ou em Vitoria. Agora, no entanto, o nexo entre a racionalidade e propriedade produz efeitos que não envolvem apenas a esfera do indivíduo, mas toda a estrutura da ordem social-natural." (tradução nossa) 
a razão, a partir de agora, que fundamenta a liberdade de escolha do indivíduo. Este será o ponto de partida para a construção do próprio relato político moderno com o desenvolvimento das doutrinas contratualistas, conforme já mencionado.

Sob a égide dessa segunda faceta do Estado moderno, ou seja, o modelo liberal de Estado de Direito, surgem, positivados, os primeiros Direitos Fundamentais, como Direitos Civis. Como se sabe, esses direitos incipientes estão direcionados ao homem abstrato e isolado, como prerrogativas que cumprem promover de forma contundente a autonomia individual. Essas prerrogativas de liberdade garantem, na maior parte das vezes, um espaço de livre decisão no qual o poder político não poderá interferir. Liberdade religiosa, liberdade de pensamento, de associação, de circulação, de direito à vida, de direito à propriedade são o que o constitucionalismo liberal ${ }^{3}$ acabará por reconhecer e positivar na sua função de garantir a ideia de governo limitado. Quanto mais limites circunscrevem a ação do poder político, o mecanismo da separação de poderes, por exemplo, maior a suposta dimensão da liberdade do homem. Os direitos individuais, ou de primeira geração/dimensão, assim nasceram e adquiriram um caráter universal, visto que se destinavam, abstratamente, a todos (fruto de uma perspectiva jusnaturalista de compreensão de prerrogativas inatas à própria natureza humana como já se observou). No entanto, a ideia de universalidade não impediu um exacerbado personalismo na possibilidade da fruição desses primeiros direitos. Era, na realidade concreta, a classe burguesa a única capaz de fruir da maior parte daquelas prerrogativas.

Não é possível esquecer que as revoluções liberais burguesas se inserem em um contexto de transformação político-econômica. Com a Revolução Industrial e suas consequências (transformação nos meios de produção e trabalho), estava-se diante de uma sociedade moderna na qual o homem é supostamente livre para eleger seus meios e buscar seu próprio fim. A lógica da razão logo se transforma em uma lógica instrumental calculista que acaba por misturar a esfera privada com a econômica. A dimensão pública ficará incumbida de resguardar a ordem, a paz social e a segurança dos contratos e da propriedade. Assim como os indivíduos, a economia se autonomiza, e a política se transforma em uma lógica de gerenciamento dos interesses do mercado. Nesse contexto, assume fundamental importância o Direito Privado, especialmente o Direito Civil, visto que o capitalismo concorrencial entrega, aos sujeitos da esfera privada, a capacidade e a autonomia para regular as relações entre particulares, estabelecendo apenas uma marco jurídico geral sob o qual se desenvolverão

3 Entende-se aqui por "constitucionalismo liberal" ou também por "constitucionalismo moderno" o movimento cultural e político que culminou, em fins do século XVIII, com o advento das constituições escritas, portadoras, por sua, vez, de mecanismos capazes de estabelecer a técnica do governo limitado (separação de poderes, por exemplo) e a consequente garantia dos direitos de liberdade dos indivíduos. Nesse sentido, a principal função das primeiras Constituições escritas era a de equilibrar poder e liberdade, ou seja, estabelecer as regras do jogo político. 
essas relações. A garantia da dimensão patrimonial e a segurança dos atos de troca, a liberdade de contratar e a autonomia da vontade são valores que orientam e determinam a validade e segurança dos negócios jurídicos e deveres jurídicos. No plano político, emerge o princípio da representação pela vontade da maioria (democracia representativa). Os direitos de participação política começam a ser estabelecidos, e o princípio da soberania popular encontrará abrigo nas primeiras Constituições. No entanto, de acordo com a ideia de que a universalidade de direitos não elimina a possibilidade de estabelecimento de diferenças, os considerados iguais nesse contexto, como destinatários dos direitos políticos, são os homens - entenda-se homem gênero masculino, branco e proprietário. O status político ativo requer que o indivíduo possua determinada renda ou bens para se qualificar como sujeito político, e as mulheres e os trabalhadores se encontrarão longe da satisfazer essa qualificação. Esclarecedora as palavras de Pietro Costa (2014),

[l]'Ottocento è l'età dei diritti. La forte presenza dei diritti nell'Europa del "secolo lungo" è incontestabile, ma mostra al contempo i segni di un'interna divaricazione e di una singolare fragilità. Da un lato, si moltiplicano le "lotte per i diritti", ma i moral rights reclamati faticano non poco a trovare accoglienza negli ordinamenti positivi; dall'altro lato, la rivendicazione dei diritti riesce a mettere in questione la legittimità delle discriminazioni esistenti, ma non dispone a proprio supporto di una teoria coerente e condivisa, che abbia preso il posto dell'ormai marginale giusnaturalismo. La stessa eguaglianza, cui le lotte per i diritti fanno appello contando sul fatto che essa è un principio costitutivo della modernità giuridica (salvo i diversi gradi di "radicalità" nella sua attuazione), subisce, a fine secolo, attacchi crescenti: dal darwinismo sociale ai movimenti nazionalisti, dalle ideologie della razza alle teorie dello Stato-potenza, si moltiplicano le prospettive convergenti nel presentare l'eguaglianza come un vecchio arnese ideologico, che occorre ridimensionare per valorizzare la gerarchia, la disciplina sociale, l'espansionismo della nazione (p. 63) ${ }^{4}$.

Apenas na segunda metade do século XIX, os trabalhadores tomam consciência, em função das correntes socialistas, da sua situação de exclusão política e social.

4 "O Oitocentos (século XIX) é a idade dos direitos. A forte presença dos direitos na Europa do "século longo" é incontestável, mas, concomitantemente, mostra os sinais de uma lacuna interior e de uma fragilidade singular. De um lado, multiplicam-se as lutas por direitos, mas os moral rights reclamados lutam não apenas para encontrar acolhimento no direito positivo; de outro lado, as reivindicações de direitos conseguem colocar em questão a legitimidade das discriminações existentes, mas não contam com um suporte teórico coerente próprio e compartilhado como havia sido o caso do agora marginal jusnaturalismo. A mesma igualdade, cuja as lutas por direitos fizeram apelo, tomando em conta que este é um princípio constitutivo da modernidade jurídica (exceto pelos diferentes graus de 'radicalismo' em sua aplicação) sofre, em fim de século, um aumento crescente: do darwinismo social aos movimentos nacionalistas, das ideologias racistas às teorias do Estado-potência, multiplicam-se as perspectivas convergentes em mostrar a igualdade como um velho instrumento ideológico que deve ser redimensionado para valorizar a hierarquia, a disciplina social e o expansionismo da nação". (tradução nossa) 
Com a Primeira Grande Guerra e o agravamento, que dela decorre, da chamada "questão social" (exploração humana reproduzida socialmente com o consequente aprofundamento dos níveis de miséria, exclusão e desigualdades concretas), o capitalismo deixa de ser concorrencial e passa a organizar-se. A Primeira Guerra marca o fim do capitalismo concorrencial e o início do fim da infrarrepresentação política das classes trabalhadoras e das mulheres. O próprio constitucionalismo (agora sob uma perspectiva mais marcadamente social) se verá obrigado a readaptar-se no sentido de encontrar novos caminhos para tentar sanar algumas das patologias geradas pela própria modernidade. Esses novos rumos do constitucionalismo implicaram, especialmente no período de entreguerras, a reformulação do princípio representativo para acabar com o voto censitário e alçar, finalmente, à esfera política, no circuito da representação, uma classe (os proletários) e o sexo feminino, alargando o consenso constitucional para além da burguesia. O signo do século XX conhecerá uma transformação paulatina no modelo de Estado liberal que vai, pouco a pouco, assumindo uma faceta mais voltada ao social e, portanto, à realização do valor igualdade material.

Será com o advento da Segunda Grande Guerra, no entanto, que os Direitos Humanos desenvolvidos até então, mas já sem brilho e ênfase do início, voltam a ganhar centralidade e especial importância; contudo, essa redescoberta de direitos não foi fácil nem imediatamente assimilada. Será apenas em 1945, na Conferência de São Francisco, que a Carta das Nações Unidas em seu artigo 555, utilizará a categoria Direitos Humanos, e assim essa categoria entrará oficialmente na pauta política mundial. Segundo Costa, os Direitos Humanos encontrarão a sua consagração definitiva no Julgamento de Nuremberg (e de Tóquio) e na Declaração da Organização das Nações Unidas (ONU) de 1948. Esses dois eventos possuíram uma enorme força simbólica para afirmar a categoria Direitos Humanos, sendo os primeiros a mencionar e prever os crimes contra a humanidade. A própria ideia de humanidade estabelece a proteção a esses direitos agora tanto no âmbito interno como no internacional. No pós-Segunda Guerra, a onipotência do Estado e do seu soberano estará em baixa e agora vinculada ao respeito a uma órbita internacional que passa a gravitar em torno da proteção aos Direitos Humanos.

O Estado passa a ser o instrumento para a realização dos Direitos Humanos, e estes se tornam a base sobre a qual se assenta a convivência humana. Os direitos

5 Carta das Nações Unidas, artigo 55. "Com o fim de criar condições de estabilidade e bem-estar, necessárias às relações pacíficas e amistosas entre as Nações, baseadas no respeito ao princípio da igualdade de direitos e da autodeterminação dos povos, as Nações Unidas favorecerão: a) níveis mais altos de vida, trabalho efetivo e condições de progresso e desenvolvimento econômico e social; b) a solução dos problemas internacionais econômicos, sociais, sanitários e conexos; a cooperação internacional, de caráter cultural e educacional; e c) o respeito universal e efetivo dos direitos humanos e das liberdades fundamentais para todos, sem distinção de raça, sexo, língua ou religião" (Carta das Nações Unidas, 1945). 
passam a ocupar o centro de atenção da ordem jurídica e política. Ocorre um declínio na teoria jurídica, da perspectiva positivista do direito acusada de chancelar (em função da difusão de um legalismo extremado) os horrores da guerra. A atenção volta-se agora para os organismos transnacionais e para a órbita internacional. O homem portador de direitos não apenas civis de liberdade e propriedade, mas também políticos e sociais, aparece como sujeito de direitos perante a órbita internacional na qual, anteriormente, só os Estados eram visíveis.

Assim, nesse contexto, singulariza-se a preocupação internacional com a criação de organismos e instrumentos de proteção aos Direitos Humanos. Não é demais rel embrar a criação da ONU e a Declaração Universal de Direitos Humanos de 1948, bem como as demais convenções e tratados internacionais sobre Direitos Humanos que se seguiram e foram ratificados por boa parte dos Estados Soberanos. Nas palavras de Portales e Rafael (2010),

[e]n términos general, la Declaración Universal de los Derechos Humanos forma parte de un consenso normativo internacional que pretendía rediseñar y reorganizar las relaciones internacionales tras la Segunda Guerra Mundial. Un impulso y desarrollo jurídico ejemplar que incluye la Convención sobre el Genocidio de 1948, la Convención de Ginebra de 1949, la Convención Internacional sobre el estatuto del refugiado de 1951. La Declaración Universal de derechos humanos otorgó a los individuos un reconocimiento jurídico internacional donde se les garantizaba, independientemente cual fuese su raza, religión, gênero o edad, unos derechos que podían ejercer contra cualquier acción gubernamental, política o leyes estatales injustas o costumbres opresivas (p. 19).

Diante desse breve relato histórico do desenvolvimento dos Direitos Humanos e Fundamentais e do fio condutor dessa compreensão, os chamados "moral rights", é possível afirmar que as duas expressões encontram uma base comum e que, conforme será desenvolvido no próximo tópico, a diferença entre as expressões resida essencialmente na delimitação espaço-territorial que os separaria, ou seja, os Direitos Fundamentais vistos como prerrogativas reconhecidas pela ordem jurídica interna de um Estado determinado e, por sua vez, os Direitos Humanos vinculados às prerrogativas que são reconhecidas pela órbita jurídica internacional.

\section{DIREITOS HUMANOS E DIREITOS FUNDAMENTAIS E A DIMINUICÃO DAS SUAS FRONTEIRAS CONCEITUAIS NO MUNDO GLOBALIZADO}

Conforme se depreende da seção anterior, existe uma origem comum entre as expressões "direitos humanos" e "direitos fundamentais", cujas fronteiras conceituais sempre estiveram muito próximas. Como se sabe, os Direitos Humanos têm sido uma das principais reflexões das mais variadas esferas do saber. Ao tema, dedicam-se tanto o Direito quanto a Filosofia, a Sociologia, entre tantas outras ciências. Assim, a trajetória de seu reconhecimento e compreensão já foi traçada pelos mais variados 
doutrinadores, bem como o seu fundamento tem sido motivo de discussões acadêmicas até os dias atuais. A expressão "direitos humanos" em contraposição à "direitos fundamentais" se baseia, em última análise, no fundamento tomado em consideração para compreender a concepção utilizada.

Nesse sentido, para a doutrina, os Direitos Fundamentais constituem uma das grandes categorias políticas e jurídicas nascida, de forma mais singular, com o despertar da Modernidade, à medida que os fundamentos de ordem teocrática e teocêntrica perdem o sentido na construção mais sólida das noções de poder e suas respectivas justificativas, dando lugar às fundamentações antropocêntricas que se incumbem da renovação do papel do indivíduo na sociedade. É por meio do desenvolvimento da instituição política e jurídica do Estado (Estado-nação, territorializado), em seus vários modelos, que o reconhecimento do homem como sujeito de direitos se estabelece e se aperfeiçoa. De início, o súdito cede lugar ao cidadão; o indivíduo completamente submetido à estrutura de poder estatal dará espaço ao indivíduo abstrato, portador de prerrogativas que podem ser exercidas inclusive contra a ingerência, agora indevida, do poder do Estado.

Assim, quando se utiliza a expressão "direitos fundamentais", a referência tomada para a sua composição implica um conjunto de prerrogativas, reconhecidas pela ordem jurídica e constitucional de um Estado concreto e determinado, voltadas para o reconhecimento e proteção das dimensões de liberdade, igualdade e dignidade humanas. A ideia de que a expressão "direitos fundamentais" esteja vinculada a uma proteção e reconhecimento por normas positivadas e, portanto, delimitada espaçoterritorialmente tem origem na França, no fim do século XVII. Para Perez Luño (1991, p. 10), a expressão foi fruto do movimento político e cultural que culminou na Revolução Francesa e, consequentemente, na Declaração de Direitos do Homem e do Cidadão de 1789. Segundo o autor, a expressão ganha especial relevo na Alemanha, que, sob o título de Grundrechte, passa a associá-la a um sistema de regulação das relações entre o Estado e o indivíduo, que comporá a ordem jurídica fundamental do Estado; nesse sentido, a Grundgesetz de Bonn de 1949. Sob essa perspectiva, os Direitos Fundamentais elencam normativamente os princípios que definem a concepção de mundo e informam as opções éticas e morais de um determinado ordenamento jurídico-constitucional.

Já o uso da expressão "direitos humanos" implicaria a mesma essência, ou seja, os Direitos Humanos também importariam em um conjunto de prerrogativas voltadas para o reconhecimento e proteção da liberdade, igualdade e dignidade humanas, mas que ultrapassam o limite espacial de reconhecimento e proteção pela ordem jurídica interna de um Estado determinado, alcançando uma dimensão de proteção internacional. Segundo o entendimento de Perez Luño (1991), 
[L]os derechos humanos aparecen como un conjunto de facultades e instituciones que, en cada momento histórico concretan las exigencias de la dignidad, la libertad y la igualdad humanas, las cuales deben ser reconocidas positivamente por los ordenamientos jurídicos a nivel nacional e internacional (p. 28).

Para o autor, os valores igualdade, liberdade e dignidade humanas formam o eixo principal das reivindicações dos Direitos Humanos que foram estabelecidas ao longo de seu evoluir histórico, isto é, a conquista de um conjunto de faculdades e instituições destinadas a realizá-los. Inclusive, a construção doutrinaria mais recente já consolidou a compreensão de que a liberdade reconhecida e garantida pelas ordens jurídicas e políticas dos Estados contemporâneos deve ser promovida e realizada concretamente não apenas pelo indivíduo, mas também pelos poderes públicos na compreensão de que não é possível a sua realização sem condições materiais concretas de vida digna, exigindo, então, pressupostos econômicos e sociais para a sua concreção. Nesse diapasão, não resta dúvida, contemporaneamente, de que o reconhecimento e a proteção apenas das prerrogativas inerentes à liberdade do homem, o que se costuma classificar (não sem críticas pertinentes) como direitos de primeira geração/ dimensão, são insuficientes para a tentativa de se garantir uma existência digna, visto que o uso das prerrogativas de liberdade pressupõe condições de acesso igualitário aos bens mais básicos da vida, ou seja, condições mínimas de exercício das prerrogativas de igualdade (direito à saúde básica, à educação fundamental etc.); nessa perspectiva, a recíproca se faz verdadeira, isto é, não bastam apenas reconhecimento de prerrogativas e instituições no sentido da realização do valor igualdade (igualdade material) se não se instrumentalizam, ao mesmo tempo, as prerrogativas de proteção à liberdade. Não por outro motivo a Declaração e Programa de Ação de Viena (1993) consagra as características de indivisibilidade, interdependência e inter-relação dos direitos. Percebe-se, assim, que direitos de liberdade e de igualdade se requerem reciprocamente, mas tensionam entre si, uma vez que, quanto mais se estendem as prerrogativas de liberdade, mais se restringirão as de igualdade e, quanto mais avançam e se concretizam as prerrogativas de igualdade, mais se fazem necessárias restrições às liberdades individuais e coletivas. Assim, liberdade e igualdade operam uma relação que produz uma tensão produtiva, especialmente na realização do valor dignidade humana.

Não obstante os traços que delineiam a diferença conceitual entre as expressões "direitos fundamentais" e "direitos humanos", é possível apontar, no mundo contemporâneo, uma tendência ao estreitamento conceitual à medida que as fronteiras entre as duas expressões parece perder significado. Especialmente quando se percebe o desenvolvimento de uma órbita protetiva internacional em um contexto no qual a ultrapassagem da ideia de Estado-nação se fortalece em função do fenômeno da globalização. 


\subsection{A alteracão nos contornos do Estado e o fortalecimento da órbita internacional protetiva aos direitos humanos no contexto da globalização}

O Estado moderno nasce, como se sabe, com a ascensão dos Estados nacionais absolutistas no contexto dos séculos XV e XVI, em função do delineamento do conceito de soberania vinculado à ideia de poder absoluto que o monarca exerce no território que ele mesmo passa a delimitar. Este sempre foi um conceito polêmico no sentido de sua exata extensão, não obstante marcou a retomada da noção de unidade atribuída ao Estado territorializado, após o longo período de descentralização política, muito próprio à Idade Média. No Estado moderno do século XIX (Estado liberal de Direito), a soberania vai adquirindo contornos mais democráticos, consequência do relato político moderno dos contratualistas, visto que a legitimação e a origem do poder passam a ser teorizadas a partir do indivíduo.

Nesse contexto, em que a noção de soberania é reconduzida ao Estado como independência em relação à ordem internacional, é possível reconhecer o Estado conformado como uma sistema jurídico fechado e autossuficiente em uma perspectiva dualista de compreensão do relacionamento e da existência das ordens internas e internacional, teoria capitaneada à época por Heinrich Triepel. No século XX, no entanto, prevalecerá a perspectiva monista desenvolvida por Kelsen e Verdross. Nesse sentido, aponta-se para a unidade do Direito Interno e Internacional com a prevalência deste último. Em outras palavras, o Direito Internacional vincula os Estados pelo princípio pacta sunt servanda e, assim, exerce uma função de coordenação, subordinando aos seus dispositivos os ordenamentos jurídicos internos estatais. Esse entendimento já exige por si uma compreensão remodelada do conceito de "soberania estatal". A compreensão da incorporação automática das normas internacionais ao Direito Interno do Estado leva ao entendimento de que este, uma vez que tenha normatização contrária aos dispositivos internacionais, poderá incorrer em responsabilidade internacional. No desenvolvimento desse raciocínio, explica Nogueira Alcalá (2000) a existência de uma renovada tendência atual ao monismo.

A su vez, hay una tendencia generalizada en el derecho constitucional comparado a admitir la incorporación automática de las normas internacionales en su orden interno, salvo casos minoritarios en el ámbito latinoamericano y europeo, lo que se hace más excepcional aún en el ámbito de los derechos esenciales o derechos humanos (p. 227).

Nesse sentido, a perspectiva da globalização, embora tenha trazido uma profunda transformação na identidade do Estado, em especial no que toca à ideia do Estado moderno nacional e territorializado, em função do esvaziamento ainda maior da ideia de soberania, para além de seus efeitos nefastos no agravamento das desigualdades e da exclusão, trouxe uma dimensão que aponta para o reforço da necessidade de se reconhecer e resguardar direitos humanos na dimensão protetiva internacional em 
harmonia com as dimensões protetivas nacionais, isto é, a aproximação cada vez maior entre as órbitas jurídicas internas (especialmente na dimensão constitucional) e as órbitas protetivas internacionais (o desenvolvimento dos diversos sistemas protetivos dos Direitos Humanos), desaguando no que se chama hoje de "Direito Internacional dos Direitos Humanos".

Assim, já há mais de três décadas, o mundo vivencia um momento de grandes transformações econômicas, culturais, sociais e políticas. O fenômeno da globalização em todos os seus aspectos, mas principalmente no seu aspecto econômico, acompanhado pela adoção, na maioria dos países, de políticas neoliberais, tem trazido grandes alterações nos contornos do Estado e nas relações de trabalho e de produção, apenas para citar alguns setores. Isso também gera a necessidade de transformação e reação à perversa e revitalizada lógica da hegemonia do mercado ou soberania do capital financeiro.

Conforme constantemente reafirmado, a partir da segunda crise internacional do petróleo em 1979, as recessões sucessivas, o aumento do déficit fiscal e do nível de desemprego, o esgotamento das políticas sociais tradicionais e a perda da competitividade internacional induzem a uma crise global do Estado de bem-estar. Com impulso de políticas públicas dos mais diversos cunhos ideológicos, o Estado passa por uma crise que leva a um profundo questionamento das suas estruturas. Privatização e desregulamentação passam a ser, como bem observa Zuleta Puceiro (1996), "aspectos centrais de uma mudança global que envolve governos, ideologias e estilos de gestão administrativa com relativa autonomia em função das condições concretas de cada país" (p. 105).

A crise do Estado intervencionista e assistencial, a partir da década de 1970, produz, em 20 anos, um mundo completamente transformado. Compõe essa grande transformação, na visão de Capella, uma mundialização "desigual" das relações sociais e uma nova revolução industrial, a terceira. Esta consiste no emprego de novos materiais de origem química ou bioquímica, na introdução generalizada da informática na produção e no consumo privado, e na adoção de novas formas de desenvolvimento do processo econômico. Comenta o autor de Fruto Proibido, em relação à mundialização:

[L]a mundialización es ya un hecho; se ha materializado en muy pocos años. Deja de haber fronteras para los flujos financieros, de bienes y de servicios, y estos flujos son incesantes. Se establece también la globalización de las comunicaciones, tanto en el sentido de la circulación mundial de los contenidos de conciencia como, más básicamente, en el de la eliminación de reductos inmunes a la acción social externa. La mundialización, significa ante todo interdependencia. La acción social se entrelaza globalmente y las consecuencias de la intervención humana resultan crecientemente distantes y laberínticas. La mundialización impone una nueva estructuración del 
espacio y de las distancias, por una parte, y del tiempo, por otra. Ciertos procesos son ahora, paradójicamente, simultáneos en todos los rincones del planeta: en todos producen efectos a la vez.

La mundialización es "deforme", o desigual; no uniforme. El "sistema-mundo" — por emplear una expresión de I. Wallerstein — tiene un "núcleo" tripolar en el "norte", constituido por Japón, la Unión Europea y los Estados Unidos, y un "sur" o periferia de países escasamente desarrollados. Se ha creado una nueva bipolaridad. El "norte" cuenta con un entorno semiperiférico que intenta aproximarse a su nivel de desarrollo, y la periferia del "sur" es lo que se ha llamado a veces un "escenario externo": países no solo de miseria sino de miseria atroz y en aumento (Capella, 2002 p. 240).

Nesse sentido, a ideia de globalização pressupõe a existência de uma economia sem fronteiras. Foi, na década de 1980, que o fenômeno da globalização começou a ser mais singularmente tratado por sociólogos, cientistas políticos, filósofos e juristas. As transformações ocorridas nessa época são muito visíveis, uma nova ordem mundial se estabelece, e os Estados mostram-se, como bem observa Arnaud (1999), cada vez menos capazes de controlar suas economias e suas moedas. A ideia de soberania, própria do Estado moderno territorializado, esvazia-se paulatinamente em um cenário no qual prevalece a ideia de interdependência e no qual aparecem novos soberanos privados supraestatais.

André-Jean Arnaud (1999, p. 12), destacando a dimensão positiva da globalização, entende que a palavra "globalização" é portadora de um significado próprio. O seu sentido comum é que ela representa a ideia de uma tomada de consciência de que a maioria dos problemas deste começo de século não mais podem ser tratados apenas pelos Estados, singularmente considerados, sem passar pela referência a vínculos que unem diferentes partes do mundo. Isso se evidencia em questões tocantes ao clima, ao meio ambiente, às comunicações em geral, às transformações no campo financeiro e econômico e, especialmente, ao campo dos Direitos Humanos.

Assim, Arnaud (1999) afirma ser possível falar em globalização quando certas condições são preenchidas.

- Uma mudança nos modelos de produção. Observa-se um deslocamento da atividade econômica, que facilita as transferências de uma parte das operações de trabalho de um país para o outro, contribuindo para a emergência de uma nova divisão do trabalho.

- O desenvolvimento de mercados de capitais ligados fora do âmbito das nações. Um fluxo livre de investimentos ocorre sem que as fronteiras sejam levadas em conta. 
- Uma expansão crescente das multinacionais. Capazes de fazer explodir sua produção graças à existência das duas condições anteriores, o poder de transação e de barganha das empresas multinacionais está reforçado no nível de uma economia que se tornou planetária.

- A importância crescente dos acordos comerciais entre nações que formam blocos econômicos regionais de primeira importância. [...]

- Um ajuste estrutural passando pela privatização e pela redução do papel do Estado. Pressões são exercidas para o desenvolvimento das instituições de mercado, em detrimento das proteções nacionais. As próprias estruturas jurídicas são afetadas e adaptadas à interação econômica.

- A hegemonia dos conceitos neoliberais, em matéria de relações econômicas. Mercado privatizado, livre mercado internacional, desregulação, desengajamento do Estado, foram as palavras de ordem do reaganismo e do tatcherismo. Elas estão invadindo progressivamente todos os continentes.

- Uma tendência generalizada, em todo o mundo à democratização, à proteção dos direitos humanos, a um renovado interesse pelo Estado de direito. O vínculo político com o que precede, está na preferência das economias liberais por Estados não-dirigistas, que se preocupam em desenvolver constituições e corpos de direito que assegurem o respeito da democracia e dos direitos humanos, e reforcem o poder dos juízes.

- O aparecimento de atores supranacionais e transnacionais promovendo esta democracia e esta proteção aos direitos humanos. Nunca as Organizações não Governamentais foram tão fortes. [...] (pp. 13-14, grifo nosso)

No mesmo sentido, Häberle (2006) reconhece os préstimos positivos da globalização em relação ao avanço de um constitucionalismo em escala universal.

A "globalização" desempenha aqui, por uma vez, o seu papel positivo, por mais elevados que possam ser, quanto ao resto, os seus custos e perigos (p. ex., a nivelação da multiplicidade cultural por força dos mercados mundiais). Ela transporta os direitos fundamentais, a rule of law, a democracia e a separação dos poderes, e também os standards sociais. A visão do mundo do Estado constitucional, por que se perguntava em 1997, torna-se constitucional (p. 18).

Nota-se que o desenvolvimento da globalização, apesar dos mais variados efeitos que aprofundaram e aprofundam as desigualdades em nível mundial, em uma 
dimensão positiva, colaborou também para um afrouxamento das fronteiras que, se acredita, ainda separam as expressões "direitos fundamentais" e "direitos humanos". Especialmente, se considerarmos que hoje, mais do que antes, a pessoa não está suficientemente protegida apenas a partir da ordem jurídica interna constitucional, por mais que o constitucionalismo contemporâneo tenha avançado no sentido de se tornar um constitucionalismo de direitos, em uma perspectiva emancipatória de se compreender as Constituições, em sua maioria, vinculadas ao respeito do princípio da dignidade da pessoa humana. Como já dito, desde o fim da Segunda Grande Guerra e especialmente no contexto atual, mediante também os efeitos negativos da globalização, a submissão dos Estados às ordens protetivas internacionais, seja na dimensão de proteção universal, seja regional, nunca foi tão necessária.

\section{A CONSTITUCIONALIZACÃO DO DIREITO INTERNACIONAL DOS DIREITOS HUMANOS E A NECESSIDADE DE DIÁLOGO HARMÔNICO ENTRE OS SISTEMAS PROTETIVOS NACIONAIS, REGIONAIS E GLOBAIS}

A necessidade de uma nova mentalidade na compreensão das relações entre as dimensões protetivas internas e internacionais, quando se trata de Direitos Humanos, já há muito vem sendo propalada pela doutrina pertinente. Antonio Cançado Trindade, em texto específico sobre o tema, dá relevo às necessidades de interação das ordens jurídicas internas e internacionais nos mais variados aspectos, especialmente no que toca à proteção de direitos nas duas órbitas, visto que os tratados de Direitos Humanos se inspiram em valores comuns superiores de proteção à pessoa e garantias coletivas que regulamentam interesses recíprocos entre os Estados-partes, sendo aplicados por estes. Nesse sentido, para o autor, o Direito Internacional e o Direito Interno encontram-se em constante interação para o alcance de um fim comum de proteção e salvaguarda dos direitos do ser humano, sendo que, em caso de conflito entre as normas envolvidas, a melhor solução propugnaria na aplicação daquela mais benéfica à pessoa, seja ela norma de Direito Interno, seja de Direito Internacional. Assim, esclarece que

[o]s tratados de direitos humanos são dotados de especificidade própria e requerem uma interpretação guiada pelos valores comuns superiores que abrigam e em que se inspiram, no que se diferenciam dos tratados clássicos que se limitam a regulamentar os interesses recíprocos entre as Partes. O caráter especial dos tratados de direitos humanos acarreta consequências jurídicas nos planos tanto do direito internacional quanto do direito público interno. Os tratados de direitos humanos partem das premissas da anterioridade dos direitos que precedem a toda organização política e social (inerentes que são ao ser humano) e de que a ação de proteção de tais direitos não se esgota — não pode se esgotar - na ação do Estado. A noção de garantia coletiva é subjacente à aplicação dos tratados de direitos humanos, e o cumprimento das obrigações internacionais de proteção requer o concurso dos órgãos internos dos Estados, chamados que são a aplicar as normas internacionais (Trindade, 2000, p. 49). 
O fenômeno da constitucionalização do Direito Internacional é reconhecido e defendido por autores que compreendem a existência de uma ordem constitucional internacional que seria formada de uma comunidade internacional, de um sistema internacional de valores e estruturas para a sua aplicação, na qual o sistema da Carta da ONU (decisivo na formação de uma comunidade internacional) não desempenharia, no entanto, como querem alguns, o papel de constituição, por não compreender toda a comunidade internacional, que vai além dos Estados. Não obstante, essa ordem internacional emergente se caracterizaria pela hierarquização crescente. Assim afirma Otávio Cançado Trindade (2008) que

[u]m sistema internacional de valores, composto por normas de forte conteúdo ético, tem adquirido posição hierárquica superior por meio da prática dos Estados. Nesse processo, a Carta da ONU desempenha papel fundamental, porquanto seus artigos $1^{\circ}(3)$, 55, 56, 62 e 68 foram a base para a negociação e a adoção de normas de direitos humanos posteriormente elevadas ao núcleo desse sistema de valores (p. 11).

A própria responsabilidade internacional do Estado se estabelece também sob a noção de hierarquia das obrigações contraídas.

Assim, a existência de um compartilhamento de valores éticos comuns e a prevalência protetiva dos Direitos Humanos possibilita a compreensão de que ocorre uma constitucionalização do Direito Internacional à medida que se fortalece um projeto ou concepção de bem para uma sociedade mundial. Note-se que essa concepção de bem não necessita ser universalmente aceita, pois se parte da ideia do próprio constitucionalismo contemporâneo, no qual prevalece a concepção de pluralidade de bens, o pluralismo aceito como um valor das democracias constitucionais (vale lembrar a perspectiva pluralista desenvolvida pelo constitucionalismo latino-americano, inclusive na compreensão de um Estado pluriétnico e plurinacional). Nesse sentido, Otávio Cançado Trindade (2008) esclarece que

[o] que se assemelha ao atual debate sobre a constitucionalização do direito internacional é o ideal a que almejavam, a ser atingido pela constituição: a eunomia, entendida como a boa ordem da coletividade mediante a resolução pacífica das controvérsias. Quiçá se possa, a partir desse ideal, concluir que a principal norma constitucional do direito internacional é a proibição da ameaça ou uso da força (p. 12).

Häberle propugna no mesmo sentido ao reconhecer que é possível apontar para alguns fundamentos teóricos que contribuem para a afirmação da constitucionalização do Direito Internacional como "Direito da Humanidade". Entre eles, a intensiva convergência entre a teoria da constituição e a teoria do Direito Internacional, visto que se ocupam dos mesmos temas com frequência (direitos do homem) e com as mesmas tarefas (proteção do ambiente e dos bens culturais, por exemplo). Trabalham com 
instituições assemelhadas (tribunais constitucionais e cortes internacionais, Tribunal Penal Internacional) e "legitimam-se, em último termo, a partir do cidadão ou do homem. Os modos de trabalho dos juristas em ambos os domínios assemelham-se (p. ex., na metodologia), pesem todas as diferenças que subsistem" (Häberle, 2006, p. 19). Aqui a necessidade de se pensar em um projeto de Estado constitucional em escala universal.

\section{CONCLUSÕES}

As características de humanização do Direito Internacional, bem como do seu fortalecimento nos últimos tempos e das transformações promovidas pelo constitucionalismo contemporâneo, apontam, conforme já afirmado, para a convergência na realização de um objetivo comum: prevenir a violência e proteger a pessoa como um valor em si é a relevância da dignidade humana para ambos os ordenamentos (interno e internacional). A interação e a harmonização entre esses ordenamentos é cada vez mais reconhecida como essencial e plenamente realizável. Conforme ressalta Acosta Alvarado (2013), referindo-se ao Sistema Regional Interamericano de Proteção aos Direitos Humanos,

$[R]$ especto de las normas nacionales, pese a las amplias diferencias entre los ordenamientos de la región, podemos señalar tres rasgos comunes que permiten la interacción entre los dos derechos. En primer lugar, la mayoría de los ordenamientos constitucionales reconocen al derecho internacional de los derechos humanos (DIDH) rango constitucional o supra legal; en segundo lugar, muchas constituciones contemplan la obligación de interpretar las normas nacionales a la luz de los mandatos del DIDH, así como la posibilidad de complementar los catálogos constitucionales con las normas internacionales; finalmente, en algunos de los ordenamientos nacionales existen las llamadas leyes puente, esto es, las normas que reconocen la obligatoriedad de las sentencias internacionales y los procedimientos para su ejecución.

Por su parte, el ordenamiento interamericano cuenta con varias normas útiles al proceso de armonización. En primer lugar está el principio de subsidiariedad (preámbulo de la Convención Americana sobre Derechos Humanos, CADH); en segundo lugar, las obligaciones generales de respeto, garantía (art. 1.1 CADH), adaptación (art. 2 CADH) e interpretación idónea (art. 29 CADH); en tercer lugar, el derecho de acceso a la justicia previsto en los artículos 8 y $25 \mathrm{CADH}$; y, finalmente, las normas dedicadas al alcance de la reparación (art. $63 \mathrm{CADH}$ ), así como a la obligatoriedad y al procedimiento de supervisión de cumplimiento de sentencias (arts. 67 y 68 CADH y 69 del Reglamento Corteidh) (p. 348).

Diante do exposto, parece não subsistir mais razão à diferenciação das expressões "direitos humanos" e "direitos fundamentais", nem mesmo no sentido de delimitação espaço-territorial, especialmente em um mundo globalizado na perspectiva de um constitucionalismo plural. 
Como lembra Carvalho Ramos, a perspectiva da pluralidade de ordens jurídicas não é exatamente uma novidade, embora possa ter tomado distintos nomes como "constitucionalismo multinível" (Pernice), "interconstitucionalidade" (Canotilho), "transconstitucionalismo" (Neves), entre outros. Para Carvalho Ramos (2012), o pluralismo consiste exatamente na "possibilidade de coexistência de normas e decisões de diferentes matrizes com ambição de regência do mesmo espaço social, gerando uma série de consequências relacionadas à convergência ou divergência de sentidos entre as normas e decisões de origens distintas" (p. 520).

O Estado e seu ordenamento interno não rege mais exclusivamente a vida nacional, especialmente em consequência de alterações profundas estabelecidas pelo do constitucionalismo contemporâneo e pela abertura do direito constitucional ao direito internacional. Talvez pudesse ser mais coerente passar-se a falar hoje em Direitos Humanos Fundamentais.

Ainda assim, subsistem as dificuldades trazidas pela própria evolução e pelo aperfeiçoamento dos direitos. Exemplo disso é o avanço trazido pelo constitucionalismo latino-americano que, ao ensejar uma mudança no sentido da prevalência de um paradigma biocêntrico (ao invés de antropocêntrico), reconhece também a Natureza como sujeito de direitos. Nessa perspectiva, percebe-se que o debate sobre a melhor expressão conceitual está ainda apenas começando.

\section{REFERENCIAS}

Acosta Alvarado, P. (2013). El pluralismo constitucional como respuesta a los desafíos de la protección multinivel en Latinoamérica: comentarios a la propuesta de René Urueña. Revista Derecho del Estado (31), 347-368.

Arnaud, A. (1999). O direito entre modernidade e globalização: lições de filosofia do direito e do Estado. Rio de Janeiro, Brasil: Renovar.

Capella, J. (2002). Fruto proibido: uma aproximação histórico-teórica ao estudo do Direito e do Estado. Porto Alegre, Brasil: Livraria do Advogado.

Organização das Nações Unidas — ONU. (1945). Carta das Nações Unidas. Recuperado de https:// nacoesunidas.org/wp-content/uploads/2017/11/A-Carta-das-Na\%C3\%A7\%C3\%B5es-Unidas.pdf

De Carvalho Ramos, A. (2012). Pluralidade das ordens jurídicas: uma nova perspectiva na relação entre o Direito Internacional e o Direito Constitucional. Revista da Faculdade de Direito, 106/107, 497-524.

Biblioteca Virtual de Direitos Humanos da Universidade de São Paulo. (1993). Declaração e Programa de Ação de Viena-1993. Recuperado de http://www.direitoshumanos.usp.br/index.php/Sistema-Global.Declara\%C3\%A7\%C3\%B5es-e-Tratados-Internacionais-de-Prote\%C3\%A7\%C3\%A3o/declaracaoe-programa-de-acao-de-viena.html 
Häberle, P. (2006). Novos horizontes e novos desafios do constitucionalismo. Direito Público, 3(13), 99-120.

Nogueira Alcalá, H. (2000). Las constituciones y los tratados en materia de derechos humanos: América Latina y Chile. Ius et Praxis, 6(2), 227-279.

Perez Luño, A. (1991). Derechos humanos, estado de derecho y constitución. Madri, Espanha: Editorial Tecnos, S. A.

Portales, A. e Rafael, E. (2010). Concepto y fundamento de los Derechos humanos. Monterrey, México: Editorial Cecyte.

Puceiro, Z. (1996). O processo de globalização e a reforma do Estado. Em J. Faria. (Ed.), Direito e globalização econômica: implicações e perspectivas (pp. 105-126). São Paulo, Brasil: Malheiros Editores.

Rossi, A. e Gomes, E. (2014). Neoconstitucionalismo e a (re)significação dos direitos humanos fundamentais. Revista da Ajuris, 41(133), 64-81.

Trindade, A. (2000). Memorial em prol de uma nova mentalidade quanto à proteção dos direitos humanos nos planos internacional e nacional. Direito e Democracia, 1(1), 5-52

Trindade, O. C. (2008). A constitucionalização do direito internacional: mito ou realidade? Revista de Informação Legislativa, 45(178), 271-284. 